\title{
Enerji Tüketiminde Optimizasyon İçin Temel Hareket Analizi Kullanılarak Yeni Bir Pompa Dişlisinin Geliştirilmesi
}

\section{Development of a New Pump Gear via Basic Motion Analysis for Optimization of Energy Consumption}

\author{
Burak ÖZTÜRK ${ }^{1 *}$, Özkan KÜÇÜK ${ }^{2}$ \\ Geliş / Received: 19/04/2019 \\ Revize / Revised: 15/05/2019 \\ Kabul / Accepted: 16/05/2019
}

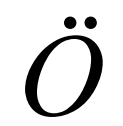

z- Endüstride; benzin, mazot, kimyasallar ve farklı tip yağların aktarılması için çeşitli tipte pozitif deplasmanlı dişli pompalar yaygın olarak kullanılmaktadır. Dişli pompalar transfer setlerinde asenkron motordan tahrik alarak yakıt transferini sağlamakta olup, bu işlem sırasında bir enerji sarfiyatında bulunmaktadırlar. Bu pompaların, içten dişli, paletli ve helis dişli pompalar olmak üzere farklı tipte üretimi yapılabilmektedir. Bunların ortak özelliği, akaryakıtı, zemin seviyesinin altına yerleştirilen depodan emerek yüksek seviyelere aktartabilmesidir. Pompalar endüstride harcanan enerji sarfiyatının önemli bir kısmını kapsamaktadırlar. Sürdürülebilir üretim uygulamalarının geliştirilmesi için optimum seviyede enerji tüketimiyle akaryakıt transferi, sektörün başlıca misyonudur. Bu kapsamda yurt dışında üretim yapan bir dişli pompa, tersine mühendislik yöntemi ile modellenmiştir. Elde edilen bu tasarımın imalatı diş içerisinde bulunan palet montajı yüzünden çok zordur. Üretim maliyetleri piyasada rekabet gücünü düşürmektedir. Bu yüzden yazarlar bu dişli geometrisini temel hareket analizi yöntemi ile geliştirerek yeni bir endüstriyel tasarım ortaya koymuşlardır. Geliștirilen bu tasarım düşük enerji tüketimi ile maksimum miktarda yakıt transferi ve emiş gücüne sahip olduğu belirlenmiştir. Günlük 100 ton kapasitesi olan bir akaryakıt transfer sisteminde belirlenen devir sayısında ve dişli tasarımı ile yıllık $3506 \mathrm{kWh}$ enerji tasarrufu sağlanabilecektir. Anova Varyans analizi sonucunda, motor devir sayısındaki değişimlerinin, enerji tüketimi ve debi miktarını \%94-95 oranında etkilediği gözlemlenmiştir. Dişli pompa için ise minimum enerji tüketiminin, asenkron motorda 500-600 RPM aralığında olduğu belirlenmiștir.

Anahtar Kelimeler- Dişli Pompa, Temel Hareket Analizi, Endüstriyel Tasarım, Enerji Tüketimi

\begin{abstract}
$A$ bstract- Various types of positive displacement gear pumps are widely used for the transfer of petrol, diesel, chemicals and different types of liquid. The gear pump provides transfer of the fuel by transferring the asynchronous motor on the transfer kits, and it is in an energy expenditure during this process. These pumps can be produced in different types including internal gear, pellet and helical gear pumps. Their common feature is that the fuel can be transported to higher levels by sucking the reservoir placed below the ground level. Achieving energy consumption and fuel transfer at the optimum level for the development of sustainable production practices is the industry's main mission. In this context, a gear pump which is produced abroad is modeled by reverse engineering method. The manufacturing of this design is very difficult because of the pallet assembly in the tooth. Production costs reduce competitive power in the market. Therefore, the authors have developed a new industrial design by developing this gear geometry through basic motion analysis method. This design has been determined to have the maximum amount of fuel transfer and suction power with low energy consumption. A fuel-transfer system with a daily capacity of 100 tonnes will provide $3506 \mathrm{kWh}$ of annual energy savings with the specified speed and gear design. Anova variance analysis applied on the calculated frame rate of $94-95 \%$ effect considering the energy consumption rate has been observed that the act of changing the engine speed and the amount of flow. Gear pump is determined that the minimum energy consumption at 500-600 RPM induction motor speed range.
\end{abstract}

Keywords- Gear Pump, Basic Motion Analysis, Industrial Design, Energy Consumption

\footnotetext{
1*Sorumlu yazar iletişim: burak.ozturk@bilecek.edu.tr (https://orcid.org/0000-0002-1018-6545) Metalurji ve Malzeme Mühendisliği Bölümü, Bilecik Șeyh Edebali Üniv, Gülümbe Kampüsü, Merkez, Bilecik 2Illetişim: ozkan.kucuk@bilecik.edu.tr (https://orcid.org/0000-0002-4337-4454)

Metalurji ve Malzeme Mühendisliği Bölümü, Bilecik Şeyh Edebali Üniv, Gülümbe Kampüsü, Merkez, Bilecik
} 


\section{GİRIŞ}

Dişli pompalar, akaryakıtı, endüstriyel yağları ve çeşitli akışkan ürünleri transfer etmek için endüstride kullanılır [1]. Kavitasyon etkisi nedeniyle gövde ve dişliler yüksek basınç altında olabilir. Güvenlik katsayıları ve pompanın ekonomik ömrü tasarımda önemli kriterler olup, üretim maliyetlerini minimize etmek, üretim endüstrileri için vazgeçilmezdir. Gövde genişliği, vida çapı ve dişli pompanın ağırlığı, tasarım parametrelerini optimize etmek için çalışılmıştır [2]. Bir çalışmada, bir dişli pompasının debisini hesaplamak için bir denklem önerilmiştir. Dişli tasarımı için kullanılan evolvent eğrisi için yeni bir formül tanımlanmıştır [3]. Çeşitli tipte pozitif deplasman pompaları değerlendirilmiş ve dişli pompaların avantaj ve dezavantajları analiz edilmiştir [4]. Yakıt ve yağ transfer etmek için kullanılan pompalar çeşitli bağlantı tipleri ile uygulanır. Yakıt tankerlerinde kullanılan pompalar, motordan güç alan bir şafttan beslenir. Bu tip uygulamada, pompanın ağırlığı ve boyutları çok önemlidir. Transfer setlerinde ise, güç asenkron motorla üretilir. Bir litre sıvı transfer etmek için pompanın harcadığı enerji büyük önem taşımaktadır. Pompaların enerji tüketimlerin azaltılmasına yönelik yapılan araştırmalar, literatürde enerji tasarrufu çalışmalarının önemli bir kısmını oluşturmaktadır. Amerikan hidrolik enstitüsü'nün araştırmasına göre gelişmiş ülkelerde pompaların tükettiği enerji, toplam tüketimin \% 20 'sidir. Bu enerjinin\% 30'unun uygun pompa seçimi ve iyi bir sistem tasarımı ile tasarruf edilebileceği belirtilmektedir [5]. Yumurtacı ve Sarıgül 2011'de yaptıkları çalışmalarında, enerji tasarrufunun, elektrik enerjisini yoğun olarak kullanan pompa sistemlerinde nasıl yapılabileceğini açıklamaya çalışmışlardır [6]. Saqib ve Khan'ın (1993) çalışması, kapsamlı bir retrofit ve onarım programı ile toplam verimliliğin ortalama \% 65 'e yükseltilmesi ile ilgilidir. Tahmini enerji kullanımında yaklaşık 4-8 milyon kWh'lik toplam enerji tasarrufu yapılabilir [7]. Üretimde maliyetlerin azaltılması ve sürdürebilirlik için enerji tasarrufu ile ilgili yapılan araştırmaların günümüzde önemi artmıştır [8,9]. Enerji ihtiyacının gün geçtikçe artış göstermesi ve enerji üretiminin yeterli düzeyde sağlanamaması günümüzde büyük bir sorun haline gelmiştir [9-10]. Bununla birlikte önemli oranda artan üretim ve ortaya çıkan enerji ihtiyacı; çevre kirliliğini arttırarak iklim değişikliklerini ortaya çıkarmıştır [10-11]. Sürdürülebilir üretim uygulamalarının geliştirilmesi sanayi kuruluşlarının ekonomik olarak ve çevresel performanslarını artırmalarına imkân sağlamaktadır. Endüstri ürünlerinin elektrik sarfiyatlarını azaltmak ve çevre dostu üretimi gerçekleştirmek için tedbirlerin araştırılması üretim süreçleri için büyük önem taşımaktadır. $\mathrm{Bu}$ kapsamda minimum elektrik sarfiyatı ile maksimum debide yakıt transferi yapabilen pompaların geliştirilmesiyle sürdürebilirlik sağlanabilecektir. $\mathrm{Bu}$ amaç doğrultusunda, yurt dışında üretim yapan bir dişli pompa üretim kuruluşuna ait olan dişli tasarımı, katalog üzerinden resim taraması ile tersine mühendislik yöntemi ile modellenmiştir. Elde edilen bu tasarımın imalatı diş içerisinde bulunan palet montajı yüzünden çok zordur. Üretim maliyetleri piyasada rekabet gücünü düşürmektedir. Bu çalışmada yazarlar, temel hareket analizi yöntemi ile bu tasarımın kinematik çalışma modelini oluşturmuşlardır. Sonrasında yeni bir paletsiz sistem geliştirmişlerdir. Son olarak ise dişli, daha önce yazarların geliştirdikleri bir pompa gövdesi tasarım ölçülerinde üretilmiştir [1]. Yazarlar daha önce geliştirdikleri bu pompa dişlisi ile geliştirilen dişli tasarımının enerji tüketim ve debi değişimlerini; Ar-Ge faaliyetlerini destekleyen kuruluşun test düzeneğinde karşılaştırmalı olarak incelemişlerdir.

\section{HELIS DISSLII POMPALARDA KIYASLAMA ANALIZİ SONUCUNDA YENİ BİR ÜRÜN TASARIMI (ILK PROTATIP)}

Yazarlar akaryakıt transfer sistemlerinin üretimini yapan bir endüstriyel kuruluşun Ar-Ge ekibiyle birlikte daha önce yaptıkları çalışmada optimum tasarım özelliklerine sahip bir helis dişli pompa geliştirmişlerdir [1]. Bu içten dişli pompanın, hacmi tanker şasesi bağlantısına sığacak ölçülerde ve montaj kolaylığı için minimum ağırlıkta tasarımı geliştirilmiştir. Çalışmada yapılan analizlere göre, aynı enerji tüketimi ile dolum kapasitesi 400 litre/dk debiden 600 litre/dk debiye çıktığı gözlemlenmiştir (Şekil 1.).
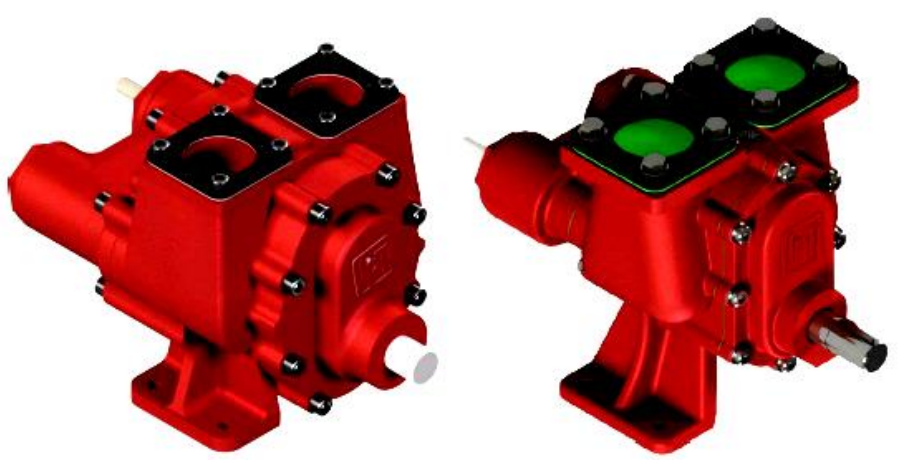

Şekil 1. Kıyaslama sonunda tasarlanan pompa (solda) ve Er 1214-D tasarımı (sağda) 
Yazarlar tarafindan endüstriyel kuruluşun test düzeneğinde 1 ton yakıt aktarımı için gerekli olan enerji tüketimi diğer ürünler ile karşılaştırmalı olarak incelenerek enerji verimliliği ölçülmüş ve Tablo 1' deki sonuçlar alınmıştır [12-15]. Yazarlar, Şekil 1'deki (solda) tasarımın dişli sistemini geliştirerek daha yüksek debide ve daha düşük enerji tüketimi ile yakıt transferini sağlamışlardır (İlk Protatip).

Tablo 1. Çeşitli pompa enerji tüketimlerinin karşılaştırılması [1]

\begin{tabular}{|c|c|c|c|}
\hline Pompa Tipi & $\begin{array}{c}\text { Debi } \\
\text { (L/dk) }\end{array}$ & $\begin{array}{c}\text { Güç } \\
(\mathbf{k W})\end{array}$ & $\begin{array}{c}\text { Enerji Tüketimi } \\
\text { (Wh/Ton) }\end{array}$ \\
\hline Z11 & 18,720 & 4,3 & 229,70 \\
\hline Z 17 & 28,920 & 7,1 & 245,50 \\
\hline YHL & 32,400 & 11,0 & 339,50 \\
\hline SG-1436 & 23,520 & 15,0 & 637,75 \\
\hline Er 1214 D & 24,000 & 7,5 & 312,50 \\
\hline İlk Protatip & 36,000 & 7,9 & 219,44 \\
\hline
\end{tabular}

\section{TEMEL HAREKET ANALIZİ İLE TASARIM GELIŞTIRME (YENİ PROTATIP)}

Yazarların daha önce geliştirdiği sessiz çalışan ve kavitasyon oranı düşük olan bir pompa gövdesi kullanılarak bu makalede enerji tüketim verimliliği için yeni bir dişli sistemi geliştirilmek istenmiştir. Bu nedenle Amerika'da seri üretimi yapılan bir dişli sistemi incelenmiştir (Şekil 2) [16]. Bu uluslararası patente sahip tasarım geometrisinin imalatı çok zor ve maliyetlidir. Ayrıca bu sistemin özelliği palet sistemine sahip iç dişin emme özelliğini artırmak için yaylanma özelliğidir. Bu üretim maliyetlerini azaltmak ve yeni bir endüstriyel tasarım geliştirmek için palet tasarımı yerine kinematik analiz ile revize edilen yeni bir tip endüstriyel tasarım bu makalede modellenmiştir. Dişliler evolvent eğrilerine göre tasarım yapılan makine elemanlarıdır. Evolvent eğrileri ile dişlilerin; sürtünme miktarı minimum olması için belirlenen bazı unsurlara göre tasarımı yapılır. On dişin altında bu eğrilerin kullanımı uygun değildir. Dixon Pompa tasarım modeli dört dişe sahiptir. Bu tasarımın yapılması için kinematik çalışma modeli oluşturulan dişlilerin minimum sürtünme miktarı için ideal diş formunun çizimi gereklidir. Böylelikle bu tasarım bir palet olmadan çalışabileceği düşünülmüştür. Yazarlar ilk olarak ürün katalog resmini tersine mühendislik yöntemi ile Solid Works 2018 programında katı modele dönüştürmüşlerdir (Şekil 2).

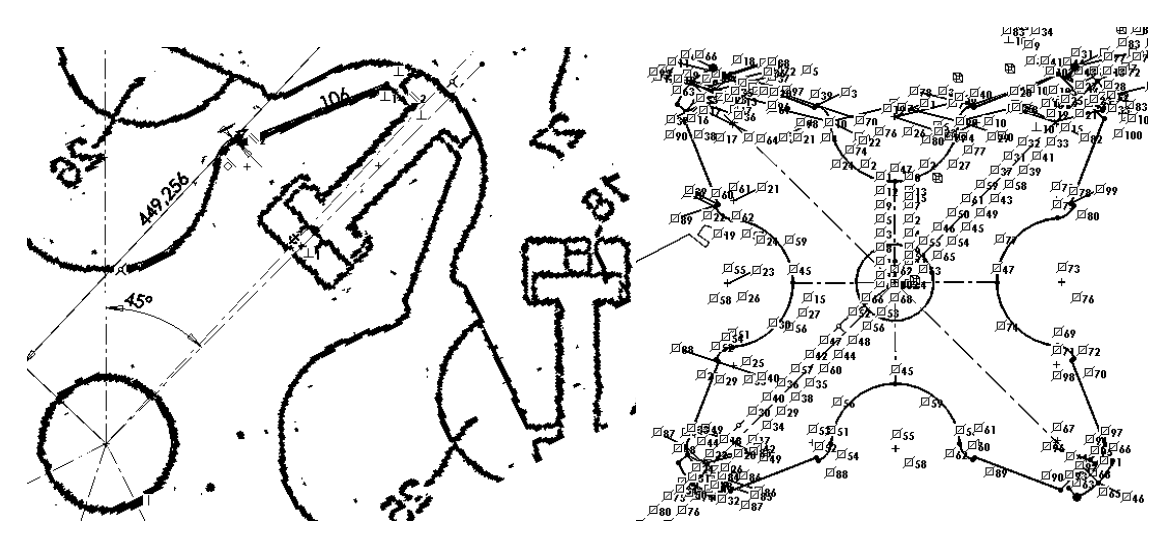

Şekil 2. Dixon Pompa dişli çifti teknik resmi (solda) tasarım geometrisinin kopyalanması (sağda) [16].

Bu katı modele dönüştürülen tasarımın kinematik çalışma modeli Solid Works temel hareket analizi sekmesinde oluşturulmuştur. Her iki dişli birbirine kontaklı olarak programda tanımlanmıştır. 3 farklı adım için temel hareket incelenmiştir. 1.Adımda pompa akaryakıtı emiş yapmaya başlamıştır. Tasarlanan yeni dişli sisteminde diğerinden farklı olarak dişli yanak yüzeylerinden kavrayacak bir radüs tasarımı oluşturulmuştur. Bu tasarım şekli sayesinde pompada vakum özelliği artırılmak istemiştir. Ayrıca dişliler dönme hareketini yaparken minimum alan teması ile dişliler arasındaki sürtünme azaltılmak istenmiştir. 2.Adımda dişli üst yüzeyi diğer dişli ile dönüş hareketini tamamlarken, vakum özelliğini devam ettirmektedir. Aynı zamanda dişli akaryakıtı bu aşmada pompalamaya ve basınç oluşturmaya başlamaktadır. 3.Aşamada sırası ile dişlinin alt kavrama radüsü diğer dişli üst yüzeyi ile birlikte kontak kurarak akaryakıtın transferini tamamlar ve sonrasında alt kavrama radüsleri dişli yanak yüzeyinde vakum yaparak emişe başlar. 

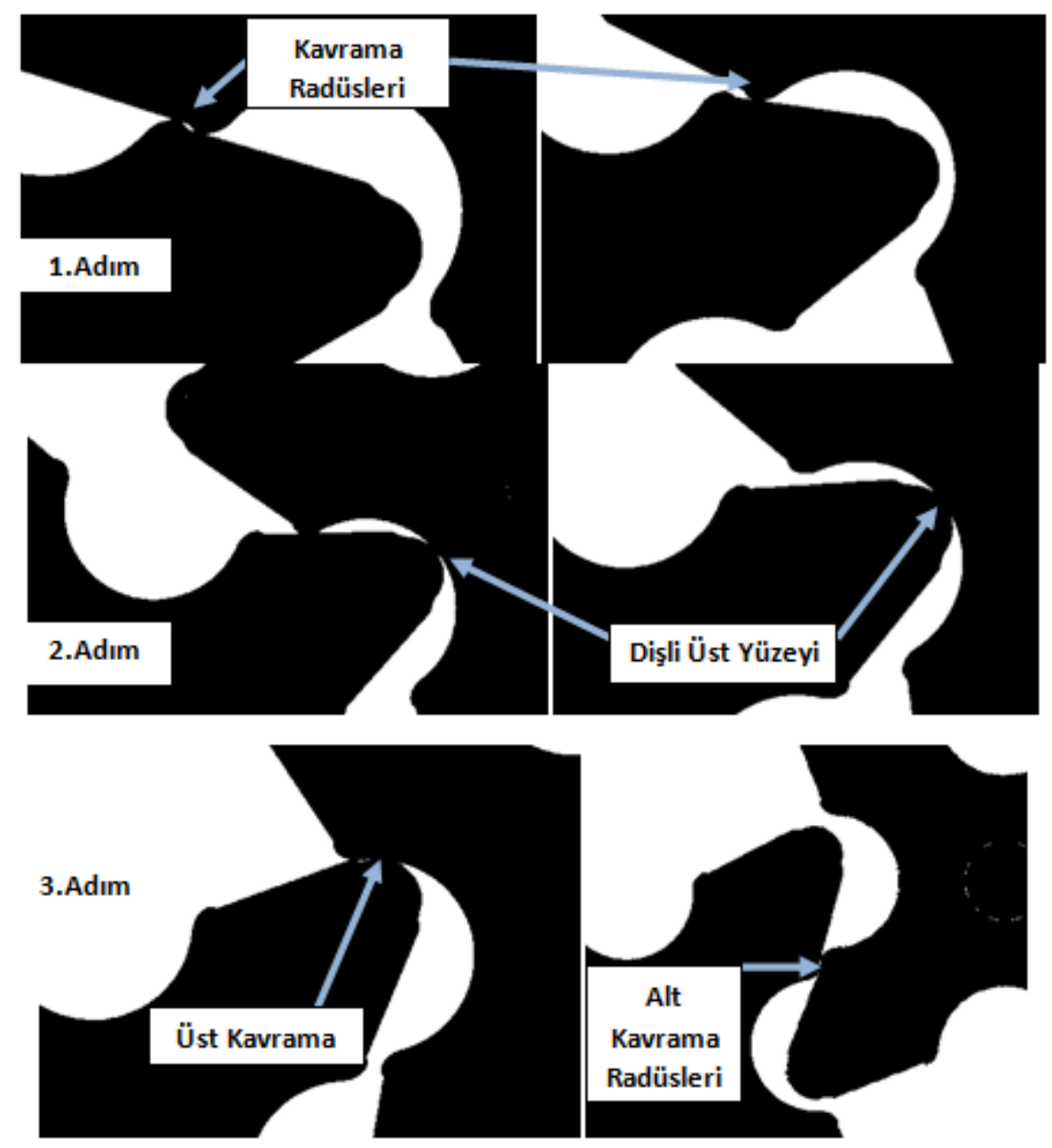

Şekil 3. Farklı eme basma konumlarında temel hareket analizi ile dişli eğrilerin şekillendirilmesi

$\mathrm{Bu}$ aşamada çok sayıda farklı geometriye sahip dişli tarsımı yapılmıştır ve temel hareket analizi uygulanarak temas yüzeyleri incelenmiştir. İdeal tasarım geometrisi belirlenirken bu radüslerin düz yanak yüzeyleri ile yaptığı sürtünme hareketinin minimum yüzey kontağı ile yapılmasına dikkat edilmiştir. Amerika'da üretimi yapılan bir dişli takımından esinlenerek imalatı kolay ve emiş gücü yüksek yeni bir tür dişli tasarımı elde edilmiştir. Yazarların daha önce geliştirdikleri helis dişli ile birlikte karşılaştırmalı olarak bu dişli setinin; yakıt transferi sırasında debi miktarı ve enerji tüketimi ölçümü yapılmıştır.

\section{MATERYAL VE METOT}

Farklı motor devir sayıları için (100-800 RPM) her iki dişli tipi montajında debi ve akım indeksleri ölçümü toplam on altı farklı deney ile yapılmıştır (Tablo 2.). Her deney iki kez tekrarlanmış ve sonuçların ortalaması alınarak hesaplanmıştır.

Tablo 2. Deney tasarımı

\begin{tabular}{|c|c|c|c|c|c|c|c|c|c|c|c|c|c|c|c|c|}
\hline $\begin{array}{l}\text { Dene } \\
\text { y No }\end{array}$ & 1 & 2 & 3 & 4 & 5 & 6 & 7 & 8 & 9 & 10 & 11 & 12 & 13 & 14 & 15 & 16 \\
\hline Devir & 100 & 200 & 300 & 400 & 500 & 600 & 700 & 800 & 100 & 200 & 300 & 400 & 500 & 600 & 700 & 800 \\
\hline Dişli & Düz & Düz & Düz & Düz & Düz & Düz & Düz & Düz & Helis & Helis & Helis & Helis & Helis & Helis & Helis & Helis \\
\hline Tipi & Dişli & Dişli & Dişli & Dişli & Dişli & Dişli & Dişli & Dişli & Dişli & Dişli & Dişli & Dişli & Dişli & Dişli & Dişli & Dişli \\
\hline
\end{tabular}

IPT Akaryakıt kuruluşuna ait transfer ünitesi ölçüm seti ile pompaların farklı devirler için toplam transfer debisi ölçümü enerji tüketimi değerleri ile birlikte karşılaştırmalı olarak incelenebilmektedir. Ayrıca hareketin sağlandığı inverter ve ampermetre montajlı asenkron motor test düzeneğinde yer almaktadır. 
Belirlenen deney tasarımı şartları altında mazot transferi gerçekleştirilerek anlık akım indeksleri (PI) ve dakikada transfer edilen mazot miktarı ölçülmüştür.

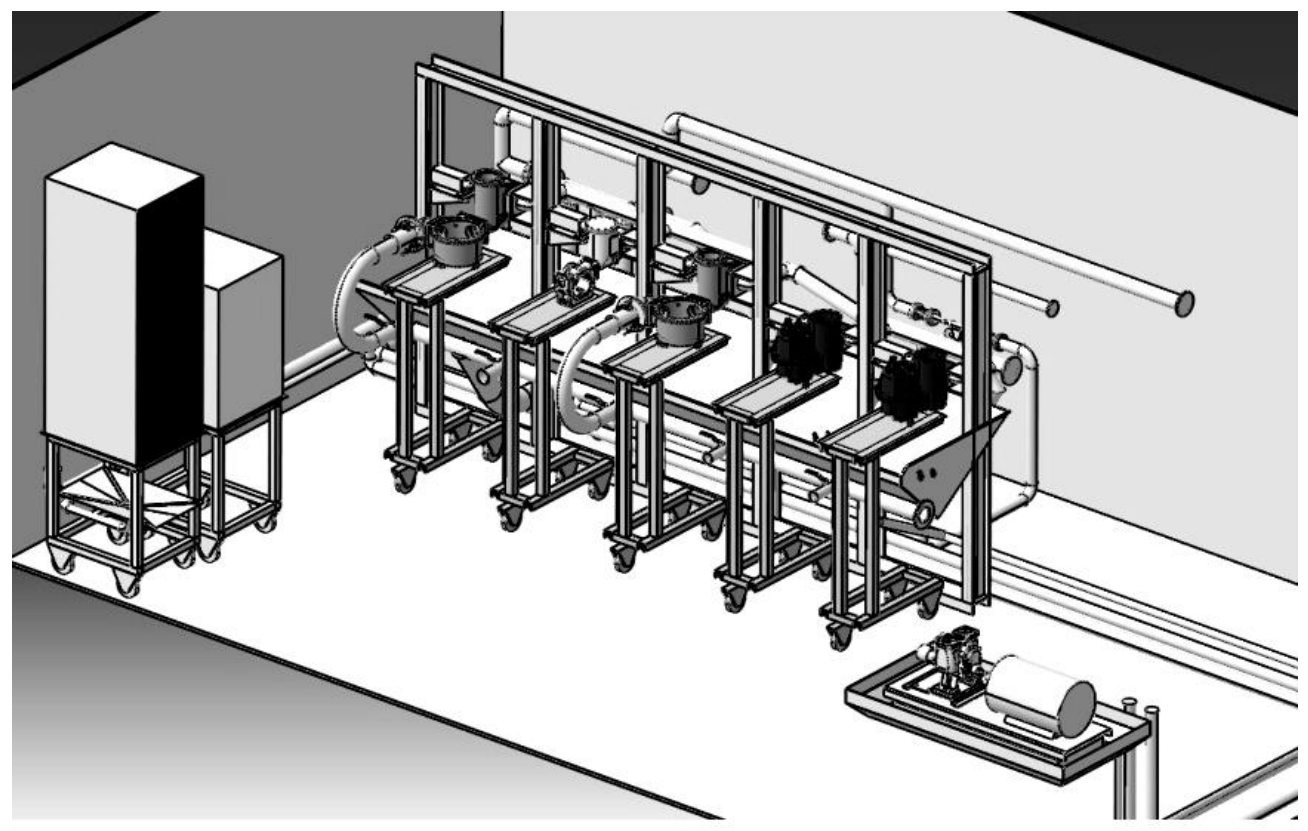

Şekil 4. Akaryakıt transfer seti debi ve enerji tüketimi ölçüm test düzeneği

Akaryakıt transferi sırasında ampermetre ile asenkron motor inverterinin çektiği güç indeksi (PI) ölçümü 1 numaralı 3 fazlı motor enerji güç dönüşüm denklemiyle güç tüketimine dönüştürülmektedir [17]. Cos $\alpha$ değeri test ünitesi asenkron motoru için $0,85^{\prime}$ dir. Bir saat süre içinde toplam enerji tüketimi, toplam transfer edilen akaryakıt miktarına bölünerek 1 litre akaryakıt transferi için gerekli olan enerji tüketimi bulunmaktadır (Eşitlik 2.). Bu hesaplamalar pompalar için 1 ton akaryakıt transferi için gerekli enerji tüketimi olarak ifade edilmektedir [1].

$$
\begin{aligned}
& P \text { transfer }=\sqrt{3} \cdot V \cdot I \cdot \operatorname{Cos} \sigma \\
& \text { SEC }=\frac{P \text { trangfey }(\text { Wh })}{\text { Debi }\left(\frac{\text { litrg }}{\text { Gatat }}\right)}
\end{aligned}
$$

\section{SONUÇLAR}

Deney setinde helis dişli ve düz dişli çifti aynı gövde içerisinde akaryakıt transferi, farklı motor devir sayıları için uygulanmıştır. Tablo 3'de bu farklı devir sayıları için 1 dakikada toplam transfer edilen akaryakıt miktarları yer almaktadır. Şekil 5' de ise her iki dişli çiftinin saatlik akaryakıt transfer miktarı değişim grafiği verilmiştir.

Tablo 3. Akaryakıt transfer seti farklı devir sayıları için debi değişimleri

\begin{tabular}{|c|c|c|c|c|c|c|c|}
\hline $\begin{array}{c}\text { Deney } \\
\text { No }\end{array}$ & Dişli Tipi & $\begin{array}{c}\text { Devir } \\
(\text { Devir/dk) }\end{array}$ & $\begin{array}{c}\text { Debi } \\
\text { (L/dk) }\end{array}$ & $\begin{array}{c}\text { Deney } \\
\text { No }\end{array}$ & Dişli Tipi & $\begin{array}{c}\text { Devir } \\
\text { (Devir/dk) }\end{array}$ & $\begin{array}{c}\text { Debi } \\
\text { (L/dk) }\end{array}$ \\
\hline 01 & Düz Dişli & 100,0 & 97,0 & 09 & Helis Dişli & 100,0 & 97,0 \\
\hline 02 & Düz Dişli & 200,0 & 193,0 & 10 & Helis Dişli & 200,0 & 196,0 \\
\hline 03 & Düz Dişli & 300,0 & 292,0 & 11 & Helis Dişli & 300,0 & 295,0 \\
\hline 04 & Düz Dişli & 400,0 & 374,0 & 12 & Helis Dişli & 400,0 & 385,0 \\
\hline 05 & Düz Dişli & 500,0 & 514,0 & 13 & Helis Dişli & 500,0 & 450,0 \\
\hline 06 & Düz Dişli & 600,0 & 612,0 & 14 & Helis Dişli & 600,0 & 525,0 \\
\hline 07 & Düz Dişli & 700,0 & 656,0 & 15 & Helis Dişli & 700,0 & 580,0 \\
\hline 08 & Düz Dişli & 800,0 & 730,0 & 16 & Helis Dişli & 800,0 & 661,0 \\
\hline
\end{tabular}




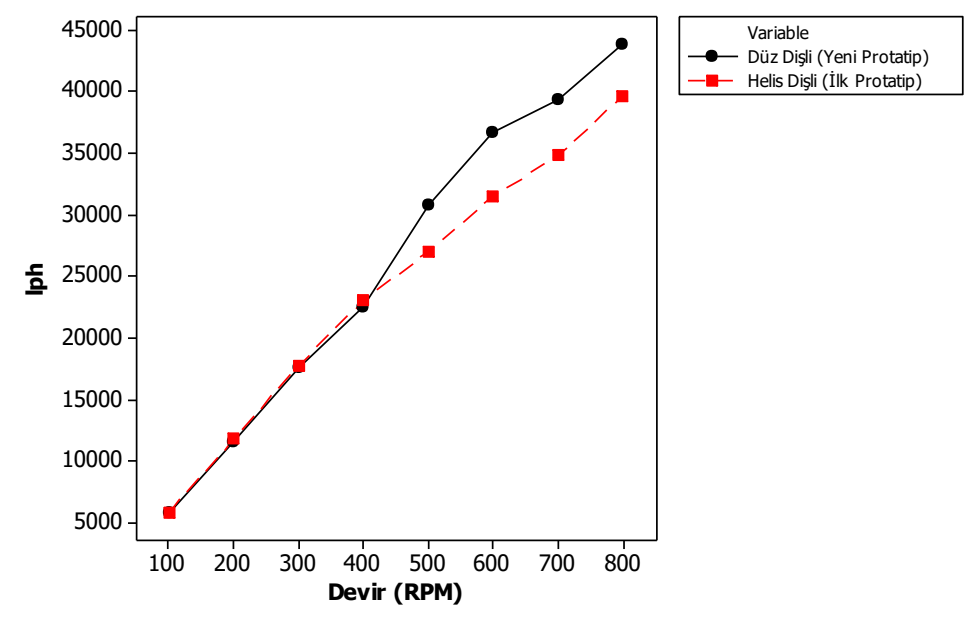

Şekil 5. Akaryakıt transfer seti saatlik debi ölçümü

Düz dişli çiftinin helis dişli pompa tasarımından daha fazla miktarda akaryakıt transferi sağladı̆̆ gözlemlenmiştir. Helis dişlide özellikle 400-500 RPM aralığındaki motor devir sayısından sonra debi miktarı azalmıştır. Düz dişlide ise aynı performansı sergileyerek bu devir aralığından sonra helis dişli çiftinden daha fazla miktarda akaryakıt transferi sağlamıştır. Yüksek devir sayılarında düz dişli çiftinin daha hızlı hareketinden dolayı emiş miktarının artığı düşünülmektedir. Düz dişli pompa geometrisinde üç farklı bölgede yer alan radüslü tasarım geliştirilerek pompa emiş gücü ve transfer kapasitesi artırılmıştır. Akaryakıt transferi sırasında gerekli olan güç; 3 fazlı enerji - güç dönüşüm denklemleri kullanılarak Minitap 18 programında line plot özelliği ile karşılaştırmalı olarak grafik haline getirilmiştir (Şekil 6.). Bu sonuçlara göre yeni geliştirilen düz dişli; helis dişli çiftine göre tüm devirler için, çok daha düşük enerji tüketimi ile akaryakıt transferini sağlayabildiği belirlenmiştir. 300-700 RPM devir sayısı aralığında her iki dişli çifti güç ihtiyacında azalma gözlemlenmiştir. Bu devir aralığında her iki pompanın emiş gücünün arttığı ve kavitasyon miktarının yüksek devirlere göre daha az olduğu düşünülmektedir.

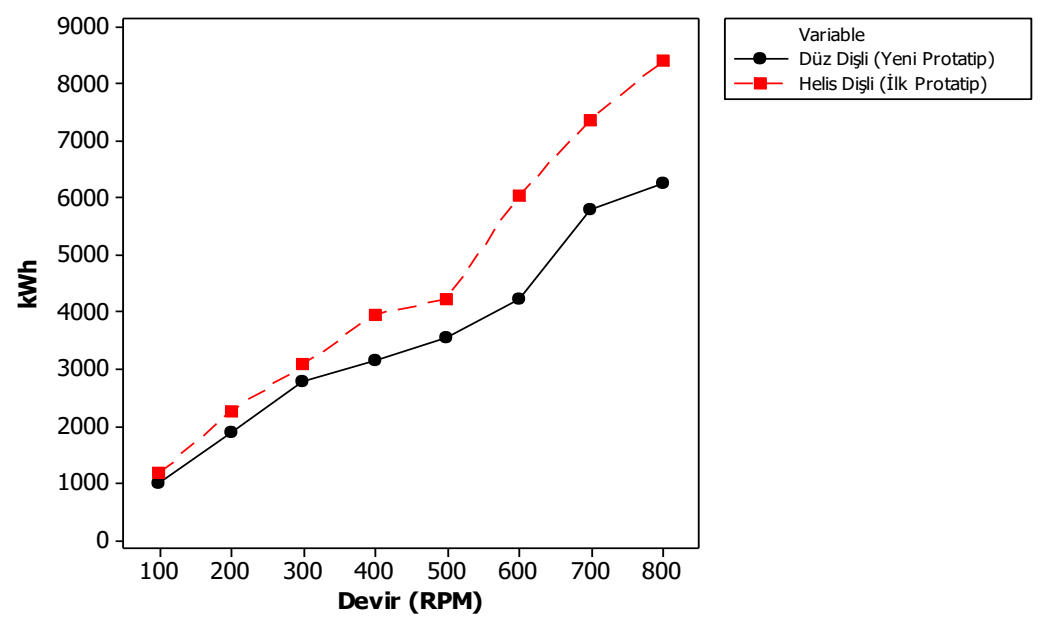

Şekil 6. Akaryakıt transferi sırasında gerekli olan güç

1 ton akaryakıt transferi için harcanan enerji tüketimi miktarı çok önemlidir. Şekil 7'de bu transfer için gerekli olan enerji miktarı Wh/Ton olarak yer almaktadır. 500-600 RPM motor devri için tüketim miktarı her iki dişli çifti için en az değerlere ulaşırken 500 RPM' den sonra artış gösterdiği söylenebilir. Ayrıca yeni geliştirilen dişli tasarımı çok daha az bir enerji sarfiyatı sergilemiştir. 


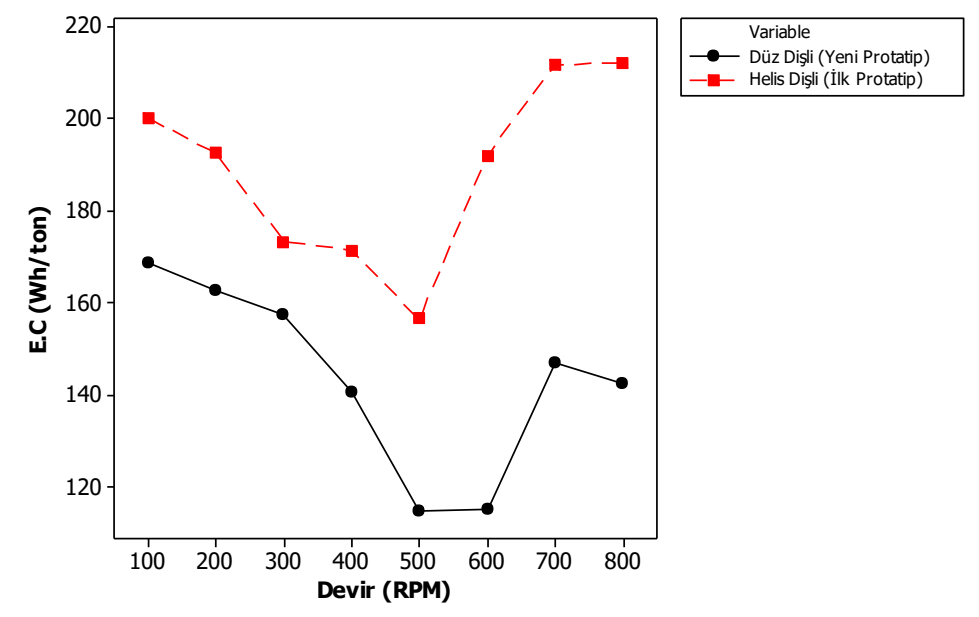

Şekil 7. 1 ton akaryakıt transferi için gerekli enerji tüketimi

Farklı devir sayılarının ve her iki dişli tipinin debi ve güç ihtiyacına \% etkilerini hesaplamak için Minitap 18 programı kullanılmıştır (Tablo 4). Debi ve güç ihtiyacı değişimine en fazla etkili olan parametre devir sayısidır.

Tablo 4. Anova Varyans analizi sonuçları

\begin{tabular}{|c|c|c|c|c|c|c|c|}
\hline & Source & DF & Seq SS & Adj SS & Adj MS & F & P \\
\hline \multirow{3}{*}{ Debi } & A & 7 & 608013 & 608013 & 86859 & 1668,36 & 0,000 \\
$(\mathbf{L} / \mathbf{d k})$ & B & 1 & 30189 & 30189 & 30189 & 579,86 & 0,000 \\
& Error & 7 & 364 & 364 & 52 & & \\
& Total & 15 & 638567 & & & & \\
\hline \multirow{3}{*}{ P $_{\text {transfer }}$} & A & 7 & 67263033 & 67263033 & 9609005 & 96,40 & 0,000 \\
$(\mathbf{k W})$ & B & 1 & 3327888 & 3327888 & 3327888 & 33,38 & 0,001 \\
& Error & 7 & 697778 & 697778 & 99683 & & \\
& Total & 15 & 71288700 & & & & \\
\hline
\end{tabular}

\section{SONUÇLARIN DEĞERLENDİRILMESI}

Günümüzde enerji kaynaklarının artıılması, imalat, enerji üretimi ve enerji tüketiminde optimizasyon önemli konu başlılarını oluşturmaktadır [18-23]. Enerjinin üretimi ne kadar önemli bir konu ise enerjinin verimli kullanımı da aynı oranda önemlidir. Literatürde farklı tip pompalar için yapılan araştırmalarda optimum enerji tüketimi araştırılmıştır [5,6]. Bizde bu makalede, akaryakıt transfer sistemlerinde kullanılan pozitif deplasmanlı pompalardan olan dişli pompaların enerji verimliliğini araştırdık. Akaryakıt transfer sistemleri için bu makalede önerilen spesifik enerji tüketim modeli 1 ton yakıt transferi başına harcanan toplam enerjiyi ifade etmektedir. Her iki pompada da 500 RPM motor devrine kadar enerji tüketiminde bir azalma gözlemlenmiştir. 500-600 RPM motor devrinden sonra bu tüketim artış göstermiştir. Akaryakıt sistemleri için minimum enerji tüketimi ile maksimum debide yakıt transferi için ideal asenkron motor devri 500 RPM olduğu belirlenmiştir. Akaryakıt test düzeneğinde 114,6 Wh/Ton olarak minimum enerji gereksinimi hesaplanırken $212 \mathrm{Wh} /$ Ton en yüksek enerji sarfiyatı gözlemlenmiştir. Her iki değer arasında \%54'lük bir büyük oransal fark bulunmaktadır.

Günlük 100 ton kapasitesi olan bir akaryakıt transfer sisteminde belirlenen devir sayısında ve dişli tasarımı için aylık 292,2 kWh enerji tasarrufu sağlanabilecektir. Anova Varyans analizi \%1' den daha az bir hata oranıyla yapılmıştır. Parametrelerin \% etki oranı dikkate alındığında \%94-95 oranlarında enerji tüketimi ve debi miktarına devir değişimlerinin etki ettiği gözlemlenmiştir. Roper Pompa 229,7-245,5 Wh/Ton ve Viking Pompada ise $637,7 \mathrm{Wh} /$ Ton enerji sarfiyatı yapmaktadır. İlk prototip olarak geliştirilen helis dişli pompa ise 219,4 Wh/Ton enerji sarfiyatı ile akaryakıt transferi yapmaktadır. Bu çalışmada tasarladığımız, Düz dişli pompa ise $145 \mathrm{Wh} /$ Ton enerji sarfiyatı ile dakikada $695 \mathrm{~L} / \mathrm{s}$ akaryakıt transferi sağlamaktadır. Bu makalede yurt dışında üretimi yapılan bir dişli tasarım geometrisinden esinlenerek tersine mühendislik ve temel hareket analizi ile yeni bir dişli tasarımı geliştirilmiştir. Bu tasarım geometrisi ile pompa emiş gücü ve saatlik debi kapasitesi artırılırken enerji tüketiminde optimizasyon sağlanmıştır. 


\section{TEŞEKKÜRLER}

$\mathrm{Bu}$ araştırmaya destek ve katkıları için IPT (İsmet Pompa Teknolojileri) Yakıt Ekipmanları Petrol Kimya Sanayi ve Ticaret Limited Şirketine teşekkür ederiz.

\section{KAYNAKLAR}

[1] Düzdar, A. İ., Kantoğlu, B., \& Öztürk, B. (2018). A New Product Design After Benckmarking Analysis Of Helis Gear Pumps And Optimization In Energy Consumption. Düzce Üniversitesi Bilim ve Teknoloji Dergisi, 6, 610-617.

[2] Çelik, H. K., Uçar, M., \& Cengiz, A. (2007). Yüksek Basınçlı Dişli Pompalarda Gövdenin Parametrik Tasarımı, Gerilme Analizi ve Optimizasyonu, Mühendis ve Makina, 576(49), 15-24

[3] Öven, V., \& Boğoçlu, M. E., (2014). Dişli Pompalarda Debi Hesaplamaları ve Tasarım Parametreleri, Mühendis ve Makina, 660(56), 34-40.

[4] Çalışkan, H. Ç., \& Ekmekçi, İ. (2003). Pozitif Deplasmanlı Pompalar. SAU Fen Bilimleri Enstitüsü Dergisi, 7(1), 206-212.

[5] Ertöz, A. Ö. (2003). Pompalarda Enerji Verimliliği, Tesisat Dergisi

[6] Yumurtaci, Z., \& Sarigul, A. Santrifüj Pompalarda Enerji Verimliliği ve Uygulamaları, 2011, Makina Mühendisleri Odası Tesisat Mühendisliği Dergisi, 49-58 .

[7] Saqib, G. S., \& Khan, S. (1993). Performance evaluation of deep well turbine pumps. Journal of Agricultural Engineering Research, 56(2), 165-175.

[8] Weinert, K., Inasaki, I., Sutherland J. W., \& Wakabayashi, T. (2004). Dry Machining and Minimum Quantity Lubrication. CIRP Annals 53(2), 511-537.

[9] Ingarao, G., Lorenzo D. R. \& Micari, F. (2011). Sustainability issues in sheet metal forming processes. an overview. J. Clean. Prod. 19(4), 337-347.

[10] Balogun, V. A., \& Mativenga, P. T. (2013). Modelling of direct energy requirements in mechanical machining processes. J. Clean. Prod., 41, 179-186.

[11] Bhushan, R. K., (2013). Optimization of cutting parameters for minimizing power consumption and maximizing tool life during machining of $\mathrm{Al}$ alloy SiC particle composites. J. Clean. Prod., 39, 242-254.

[12] Viking "Vompa "Viking Pump Enerji http://www.vikingpump.com/ Son erişim tarihi: 01.01 .2017

[13] Y1ld1z "Yompa "Yldız Pompa $\quad$ Enerji http://www.yildizpompa.com.tr/asp/index.asp?bno=25\&uno=255\&dil=Tr Son erişim tarihi: 01.01 .2017

[14] Roper Pump "Roper Pump Enerji https://www.powerflo.com/product/roper-z11-gear-pump/ Son erişim tarihi: 01.01 .2017

[15] IPT Akaryakıt Sistemleri "IPT Akaryakıt Sistemleri Enerji Tüketimi”, http://www.ipt.com.tr/Urunler/TR/Er_1214_d-Er_1214_D/17

[16] Dixon Pump "Dixon Pump Tasarımetrisi”, http://fluid-management.dixonpumps.com/viewitems/all-categories/positive-displacement-pumps Son erişim tarihi: 01.01 .2017 
[17] Shokoohi, Y., Khosrojerdi, E., \& Shiadhi R. (2015). Machining and ecological effects of a new developed cutting fluid in combination with different cooling techniques on turning operation. Journal of Cleaner Production, 94, 330-339

[18] Nas, E., \& Öztürk, B. (2018). Optimization of surface roughness via the Taguchi method and investigation of energy consumption when milling spheroidal graphite cast iron materials. Mater Test, 60, 519-524.

[19] Öztürk, B., Küçük, Ö., Düzdar, İ., \& Altınbilek Y. S. (2017). Exploring the economial reasons of the usage of unhealthy \& low resisting far-east products in the water pipe systems, The Turkish Journal Of Occupational / Environmental Medicine and Safety, 2 (3), 60-72.

[20] Dokur, E., Gökhasan, O,, Örs, O., \& Kurban, M. (2016). Ulaşım Sistemlerinde Titreşim Tabanlı Enerji Hasadı ve Uygulamalı Analizi. Bilecik Şeyh Edebali Üniversitesi Fen Bilimleri Dergisi, 1 (1), 52-58.

[21] Erbaş, O., Topal, H., Şentürk A., M., \& Arslan, O. (2017). Akışkan Yatakta Rejim Bölgesinin Isı Transferine Etkisi. Bilecik Şeyh Edebali Üniversitesi Fen Bilimleri Dergisi, 4, 24-27

[22] Kara, F, \& Öztürk, B. (2019). Comparison and optimization of PVD and CVD method on surface roughness and flank wear in hard-machining of DIN 1.2738 mold steel, Sensor Review, 39,(1), 24-33.

[23] Kara, F. (2018). Optimization of surface roughness in finish milling of AISI P20+ S plastic-mold steel. Mater. Technol. 52, 195-200. 